\title{
Language-Specific Effects in Cross-Language Research and Their Implications for Second Language Acquisition: A Theoretical Enquiry
}

\author{
Enikő PÁL \\ Sapientia Hungarian University of Transylvania (Cluj-Napoca, Romania) \\ Department of Humanities \\ enikopaldr@gmail.com
}

\begin{abstract}
Both in the theoretical framework of applied linguistics and empirical studies, second language acquisition is either examined within the universalist postulation of an innate language acquisition device or it is discussed in a pluralist manner featuring the great variety of languagespecific influences. The present paper focuses on the latter issue, aiming to review some of the recent studies on the role of the mother tongue in second language speech perception and production. Our main interest is in phonetic learning. Thus, we shall particularly turn our attention to certain theoretical-empirical data regarding second language speech perception and production, such as the perceptual assimilation model, the native language magnet theory, and the articulatory setting theory.
\end{abstract}

Keywords: second language acquisition, phonology, speech perception and production, nativelikeness, L1 influences.

\section{Introduction. A general view of SLA theory}

The growing popular interest in second language acquisition (SLA) calls for a brief overview of the most recent findings in cross-language research on the effects of one language on another. Such an endeavour would have to take into consideration the fact that "as far as the strictly linguistic possibilities go, any linguistic feature can be transferred from any language to any other language" (Thomason and Kaufman 1988: 14), which sometimes makes it quite difficult to assign a certain language-specific effect to a single particular class or type of linguistic influence. What is more, the existent taxonomy of these cross-linguistic phenomena is so abundant and varied that no study could encompass all aspects 
found in literature. That being the case, our study shall focus on the domain of phonology only, though the general mechanisms that govern the influences of speech perception and production in L1 on the perception and production of speech sounds in L2 are comparable to the other domains of language as well. The aim of the present enquiry is to briefly review and synthesize the main approaches to SLA and the types of language-specific effects on phonetic learning in a second or foreign language respectively.

\subsection{Approaches to SLA}

Second language acquisition has a vast literature and involves complex theoretical issues that we cannot do justice to here. Nevertheless, it will be helpful to sketch two general approaches to it in which all important studies may be included in one way or another. The core issues of second language learning are related to L1 learning (i.e. child language development) compared to L2 (or foreign language) learning, on the one hand, and to L2 learning by children compared to L2 learning by adults, on the other hand. On the whole, all important studies on these issues may be ascribed either to a universalist or a pluralist perspective.

The universalist approach to language learning is based on the assumption that there is an innate language acquisition device (LAD) which makes possible both native and foreign language learning, and it holds the existence of certain language-specific learning procedures that are accountable for acquiring one's native language. Those who embrace the universalist view promote the idea that "language differences are mere differences in surface expression of a single human experience and/or set of thought patterns" (Leavitt 2006: 48) and, as such, language learning relies mostly on discovering the principles and setting the parameters.

The pluralist approach, on the contrary, argues that there is no such thing as innate language faculty or, if there is, it is only insignificantly available for second language acquisition - at least after a certain period of time -, and that native language learning is essentially different from foreign language learning. For those who adopt the essence-seeking pluralism rather than the law-seeking universalism, "languages differ so fundamentally from one another at every level of description (sound, grammar, lexicon, meaning) that it is very hard to find any single structural property they share" (Evans and Levinson 2009: 429).

A bridge between the two theoretical constructs of language learning may be established by the observation that in case of adults' foreign language learning "first language knowledge fills the role which Universal Grammar (UG) has in child language acquisition" and "general problem-solving principles fill the role of language-specific learning procedures of children" (Bley-Vroman 1990: 5). Nevertheless, irrespective of the universalist or pluralist approach, an important theoretical issue for cross-language and/or second language acquisition research 
consists in the nature of certain language-specific effects, i.e. the influence of L1 on L2 learning. While it is unquestionable that speakers' attunement to their native language brings about a certain ease or difficulty - depending on the degree of compatibility between the two languages - of second language acquisition, when and how L1 or the ambient language begins to leave its mark on speech perception and production in the L2 or, in other words, when and how the transition from a pre-linguistic to a truly linguistic stage occurs remain debateable questions.

\subsection{Approaches to bilingualism and its consequences for SLA}

During decades of research, bilingualism has been defined in various ways (see Heller 2006), but, in fact, all contributions view this phenomenon either in an absolute or a relative manner depending on whether speakers are regarded as true bilinguals, i.e. they master equally and perfectly both languages, or as presumed bilinguals (with a large scale of performance from false bilingual to pseudo-bilingual, passive bilingual, semi-lingual, etc.). Most recent research, however, focuses on the actual degrees of bilingualism rather than on bilingualism viewed as an abstract reality. Speakers indeed may attain different performance levels in different languages and although bilinguals may attain apparently equal performance in more than one language, in reality, it is quite unlikely that they will use each in exactly the same way since language competency is rather task- and situation-specific (cf. Cutler et al. 1992: 382). In view of this reality, most recent second language research focuses on the types of influences that one language (mainly L1) may exert on another (L2, L3, and so on).

\section{Types of language-specific effects on SLA}

Many explanations have been offered for language-specific effects - i.e. the role of the mother tongue in SLA - and how to control crossover and contamination of systems; there is little agreement, however, on how to explain these effects or even on what there is to be explained. Taking for granted the basic assumption that second or foreign language learning is produced by transposing (linguistic) habits from the first language to the one being acquired, specialists have often sought to determine the role of the mother tongue in the learning of another language in either generally positive or negative terms, with little attention to inter-individual differences or intra-individual variability.

Thus, the general view regarding the phenomenon of transfer - a basic concept in SLA research and the study of language-specific influences (see Alonso Alonso 2002) -, for instance, is that one's mother tongue influences second or foreign language learning in two opposite ways: the acquisition of a second language 
undergoes severe problems in the case of negative transfer or interference (i.e. if and when the two languages have different structures), whereas it provides a solid and beneficial basis for the student's learning in the case of positive transfer (i.e. if and when the two languages have similar structures). This view then led to the growth of two trends in applied linguistics, namely to error analysis (see Corder 1967) and to contrastive applied linguistics, since it has been considered that errors result from interference which can be predicted if differences between L1 and L2 are previously identified. Of course, things are even more intricate if we also take into account inter-language theory (see Selinker 1972, Tarone 1983) according to which the system of those who acquire the new language presents elements which do not pertain either to the native language or to the target language, which makes inter-language influences hard to detect.

Among the most cited phenomena that reflect how usage of one language is affected by an individual's knowing another, we could also mention borrowing, imposition, restructuring, convergence (see Lucas 2015), code and/or language switching (Kormos 2006: 82-84), and the like. Regardless of whether they function as learning or communication strategies, learners make use of such techniques in order to solve or facilitate a learning difficulty encountered when acquiring a new language. A thorough review of the literature on these key concepts of SLA theory is beyond the scope of this paper. It is worth noting, however, that all these types of effects share the common basis of being defined as some kind of transfer situation, more or less determined by the idea of "cognitive dominance" (Coetsem 2000) of either of the two or more languages spoken by an individual.

\section{Language-specific effects in the domain of phonology}

One of the most difficult areas in learning a second or foreign language is the phonological component. Thus, in what follows, we shall focus our attention on this particular domain, which is closely related to the ultimate attainment of nativelikeness or near-nativeness. Many theoretical and empirical studies (Abrahamsson and Hyltenstam 2009, Abrahamsson 2012) have shown that rating a bilingual speaker as native(like) in both languages very much depends on his/ her phonetic and phonological knowledge, i.e. how he/she perceives and - what is more important - how he/she produces the sounds of a given language.

\subsection{L1 effects on cross-language speech perception}

Early studies on speech perception emphasize the fact that "speech is a special type of acoustic signal that has species-specific properties unique to humans" (Pisoni 1979: 330). It is argued that the perception of speech sounds requires 
the use of specialized neural mechanisms for perceptual processing - a certain "speech mode" (Liberman and Mattingly 1985) - different from general auditory processes (Mattingly 1972, Eimas 1974, Miyawaki et al. 1975). That is to say, listeners respond to linguistic signals differently from other non-speech sounds, categorizing and labelling the former ones almost immediately, though - as later studies have shown - categorical perception may not be characteristic only of speech sounds or humans (Ohala 2008: 24).

Nevertheless, not only does categorical perception of speech sounds per se dominate the most recent studies on speech perception but differences between speech perception by children, on the one hand, and by adults, on the other hand, are also a core issue in these studies. Thus, evidence from several empirical research (Best et al. 1995, Best and McRoberts 2003, Kuhl and Meltzoff 1997, Maye et al. 2002, Kuhl et al. 2007, Kuhl 2010) suggest that there is a developmental change in speech perception that takes place early in infancy. While young infants aged under 6-8 months are extraordinarily good at discriminating all speech sounds and they perceive certain contrasts better than adults, by the end of their first year, infants start to show a certain decline of these abilities and to resemble adults' perception. This decline has been explained as a result of children getting more and more familiar with the phonetic organization of their native language, which affects their sensitivity to the distributional properties of a particular language (their mother tongue) with detriment to other distributional patterns. Thus, as far as evidence suggests, later on, adults' perception of speech sounds is constrained by the phonetic knowledge of their native language. For example, it is easier for adults to discriminate contrasts between speech sounds which have phonological function in their native language, i.e. they distinguish word meanings, than contrasts that do not have any phonological function (Maye et al. 2002: B102). Among the various theories which attempt to give an account of why infants stop discriminating previously discriminable contrasts and how adults exhibit influence from the native language, two cognitive approaches shall be discussed in what follows, namely the perceptual assimilation theory and the native language magnet theory.

\subsubsection{The perceptual assimilation theory (PAM)}

Empirical data accumulated over decades of intense research on speech perception from various languages have shown that, while young infants show a spectacular sensitivity to the discrimination of both native and non-native phonemic contrasts, around one year of life, they appear to lose the ability to discriminate non-native contrast. Among the several earlier attempts made to give an account of this state of affairs - such as lack of stimuli or the postulation that after a certain period of time UG becomes inaccessible to infants -, none 
proved to be satisfying enough or complete. A consistent explanation as to why this peculiar perceptual reorganization apparently occurs by 10-12 months was proposed by Catherine T. Best (1995) and her colleagues (Best, McRoberts, and Sithole 1988, Best et al. 1995, Best and McRoberts 2003, Best and Strange 1992, Best et al. 2001), which is known as the perceptual assimilation model.

In determining what makes infants' speech perception go through a sudden change, they assumed that since phonological categories are not innately given for children to recognize the organizing principles of their native sound system, infants must start with the ability to detect a wide range of possible speech sounds from which they can discover the specific phonetic patterns of their native language (Best 1995: 183-184). The broad range of perceivable speech sounds subsequently gets narrower as children become more aware of the phonetic organization of their mother tongue. This narrowing of the perceptual space takes place under the constraining power of assimilation. Experiments on native English listeners (adults and infants) tested on Zulu clicks (and other contrasts) showed that a phonemic process emerges around 10-12 months that assimilates speech sounds to native categories whenever possible, i.e. non-native speech sounds are perceived either as similar to or different from native sounds (with a whole range of different assimilation types); otherwise they are perceived in auditory terms, simply as non-speech sounds (Best, McRoberts, and Sithole 1988).

Since non-native segments tend to be perceived according to their similarities to and differences from the native segments, and these similarities and/or discrepancies may vary in their degree, there are several ways in which perceptual assimilation of non-native segments may take place:

a) non-native speech sounds may be assimilated to a native category as either a good exemplar of that category, an acceptable but not ideal exemplar of that category, or an apparently deviant exemplar of the category;

b) non-native speech sounds may be assimilated as uncategorizable speech sound, i.e. they are perceived within phonological space as speech sounds but not as a clear exemplar of any particular native category, as in-between native categories;

c) non-native speech sounds may not be assimilated to speech at all, i.e. these sounds are perceived as falling not only outside the native phonological space but also outside speech per se (like other audible noises or non-speech sounds) (Best 1995: 194-195).

As one might predict from these assimilation patterns, non-native contrasts that are both assimilated as equally good exemplars of a single native sound (Single-Category assimilation) should be discriminated poorly since the native phonological space lacks such contrasts, instead it has a near approximant of the non-native contrast sounds (e.g. the case of English /r/-/l/ discrimination by Japanese speakers); whereas those contrasts that are assimilated to two different 
native sounds (Two-Category assimilation) should be easily and without fail discriminated since they are cross-linguistic reflexes. In case both non-native sounds may be assimilated equally well (or poorly) into a single native category but they differ in their perceived degree of similarity to it (Category-Goodness difference in assimilation), discrimination is expected to be moderate-intermediate between the single- and two-category discrimination - to very good, depending on the magnitude of difference in category goodness for each of the non-native sounds. Likewise, when both non-native sounds fall within phonetic space but outside any particular native category, their discriminability as uncategorized speech sounds would range from poor to very good depending on their proximity to each other and to native categories. In the case of contrasts where one of the non-native sounds is assimilated to a native category and the other falls outside native categories, discrimination is expected to be very good. Finally, when both non-native categories fall outside speech domain, i.e. they are non-assimilable, discrimination is expected to be good to very good, and this type of assimilation seems not to be affected by age, i.e. both young infants and adults perform equally well in discrimination tasks that involve this kind of contrasts (cf. Best and Strange 1992: 306, Best et al. 1995: 342, cf. Best and McRoberts 2003: 187).

Thus, in view of the perceptual assimilation model, experience with the native language affects perception of non-native speech, not only constraining the perception of non-native segments from unfamiliar languages but also altering the perception of non-native speech sounds however similar to or different from those found in one's own language.

\subsubsection{The native language magnet theory (NLM)}

Acquiring a native tongue most certainly marks speakers' linguistic realm, but exactly how this experience with one's first language affects the acquisition of other languages and especially what neural mechanisms are involved in this process are still debatable questions. With respect to the particular domain of speech perception, Patricia K. Kuhl $(1994,2010)$ and her colleagues (Kuhl and Meltzoff 1997, Kuhl et al. 2007) designed a model that explains the complex set of interacting brain systems responsible for phonetic learning, known as the native language magnet theory.

This model rests on the idea that infants have innate perceptual abilities that allow them to acquire any and all sound systems to which they are exposed, i.e. they begin life with language-general patterns of phonetic perception embedded in their brain systems. Gradually, however, this language-general pattern we possess as infants becomes language-specific as speakers are immersed in a specific language (their mother tongue). The postulation of infants' initial endowment with a broad range of perceivable speech sounds that gets narrower 
as time passes by converges with the basic assumption of PAM. Furthermore, just as PAM, NLM also hypothesizes that perception of non-native speech sounds declines as a result of the influence exerted by native phonological space on nonnative segments. But unlike PAM, NLM also shows that as non-native speech perception declines between 6 and 12 months of age, native-language phonetic perception exhibits a significant improvement (Kuhl et al. 2007: 981).

NLM specifies that native phonetic categories are structured through ambient language experience and that speech perception goes through three stages of development. In the first stage, infants are able to discriminate all speech sounds, and they do so by means of innate general auditory processing mechanisms. In stage two, infants' sensitivity to native contrasts acquired from linguistic input produces phonetic representations of the distributional categories of the native language. As experience accumulates, "the representations most often activated (prototypes) begin to function as perceptual magnets for other members of the category, increasing the perceived similarity between members of the category" (Kuhl et al. 2007: 982). Finally, in stage three, this change in perception termed the perceptual magnet effect - facilitates native phonetic abilities while constraining or reducing foreign language phonetic skills.

Thus, an important finding of this theory is that early perception of native and non-native contrasts predicts later language performance but in opposing directions, i.e. better native phonetic abilities predict faster development of language, whereas better non-native phonetic abilities predict slower linguistic advancement. This is due to the fact that at birth infants possess general cognitive abilities for processing language, i.e. the neural circuitry is not yet committed to any particular language, which makes them sensitive to all phonetic differences. As experience with a specific language accumulates, brain functions develop a certain neural commitment to the native language, which once established determines all subsequent language analysis. Thus, better native performances reflect a developed language-specific neural circuitry, while better non-native performances reflect a developmental regression to the earlier language-general phase (Kuhl 2010: 720).

\subsubsection{Discussion on PAM and NLM}

The two approaches to human speech perception have many aspects in common, but - in some respects - they fundamentally differ from each other. An important strength of both theories is that they account for the loss of phonetic discrimination that was presumed to be innately present in humans, but while PAM focuses on explaining this developmental change in terms of non-native segments being assimilated to native segments with no or little regard to what happens to native speech perception in its turn, NLM focuses precisely on explaining the process of 
native phonetic development in which representation (and prototype) formation and its magnet effect play a major role. Both PAM and NLM discuss human speech perception in terms of a certain neural commitment which is responsible for the perception of both native and non-native speech segments, but in view of NLM this neural commitment has bi-directional effects: it increases the ability to perceive and discriminate phonetic patterns that are compatible with the already acquired phonetic structure while decreasing perception of phonetic patterns that do not match the acquired scheme (Kuhl 2010: 719). Although recent experiments (Lively and Pisoni 1997) call into question the robustness of the prototype-based account of the perceptual magnet effect on spoken language processing, taken together, the two cognitive models discussed above complete each other contributing to a better understanding of human speech perception.

\subsection{L1 effects on (bilingual) speech production}

The ability to pronounce L2 speech sounds has often been regarded as the ability to translate the perceptual representations of these sounds - however imperfect or incomplete they may be - into the corresponding articulatory gestures. For L2 pronunciation to be successful, i.e. without any foreign accent, many scholars claim there to be a correlation between age and second language acquisition. Age constraints on the degree of ultimate proficiency have been discussed either in terms of the so-called critical period hypothesis regarding language development in tight connection with general cognitive maturation (Lenneberg 1967; Snow and Hoefnagel-Höhle 1978, Epstein et al. 1996, Flege, Yeni-Komshian, and Liu 1999) or in terms of the age of onset sustaining or denying the importance of the age of the first exposure to the target language (see Abrahamsson and Hyltenstam 2009, Abrahamsson 2012). Our intent is not to review the substantial body of published research dealing with this particular issue or to take sides in this matter. Thus, we shall limit our account to the observation that speech production is most certainly influenced - in one way or another - by time-related factors, though not necessarily in terms of biological age, ${ }^{1}$ rather in the sense that "the more fully developed the L1 system is when L2 learning begins, the more strongly L1 will influence L2" (Flege, Yeni-Komshian, and Liu 1999: 79).

The strong influence exerted by L1 on L2 pronunciation is essentially due to the existence of language-specific articulatory settings. Although measuring phonetic settings raises a series of difficulties which explain why cross-language research on speech production has received so little attention, recent studies mostly focus on describing the basis of articulation (Kedrova and Borissoff

1 Studies indicate, for example, that the critical period for phonetic learning occurs prior to the end of the first year, whereas syntactic learning flourishes between 18 and 36 months of age (Kuhl 2010: 718). 
2013) or articulatory setting (Erazmus 1980, Wilson and Gick 2006, 2014, Lowie and Bultena 2007, Schaeffler et. al. 2008, Wilson and Kanada 2014) or phonetic setting (Mennen et al. 2010) that govern the articulatory movements in different languages. Although the concept of "articulatory setting" is defined in different ways by different scholars, common to all descriptions is the fact that the overall layout of the vocal apparatus that speakers of different languages possess is different not only in the sense of certain species-specific morphological peculiarities but also in terms of language-specific characteristics and interindividual variability. Thus, languages may differ in their predetermined positioning of the articulators or in their tendency to make the speech apparatus adopt a specific habitual configuration in pre- or inter-speech posture, which, together with the movements they impose or allow, produces the characteristic sounds of a given language. For instance, different languages are characterized by different placements of the tongue (anchorage), employ different degrees of lip protrusion and/or rounding, adopt different fashions of jaw lowering, and so on. In order to sound native-like, L2 speakers must use the articulatory setting of the language in use, which is clearly different from the articulatory setting of their mother tongue. Keeping a foreign accent in spite of many years of exercise, thus, may be due to the fact that the speaker in question fails to adopt the articulatory setting of the target language. In this case, the sounds of L2 are produced while employing the articulatory setting of L1. While the articulatory setting of one's own mother tongue is most certainly learned - i.e. it is not only unconsciously acquired by instinctively imitating the articulatory movements of adults but sometimes consciously exercised through direct instructions about what to do with certain articulators in order to produce the expected sounds -, it is still debatable whether L2 articulatory setting is a peculiarity that must be learned directly and as a whole or it is an emergent property of correctly producing the sounds in the language's inventory due to their similarity to the L1 sounds and learners should directly acquire the articulatory movements of producing only those sounds that are language-specific, i.e. different from L1.

\section{Closing lines}

The beginning point of all second language learning is one's own native language, whether speakers are aware of making use of it in their learning process or not. Thus, discussing the role of the mother tongue in second language acquisition is inevitable. It affects all aspects of language but in various ways. In the domain of phonology, L1 effects may be observed as influences of L1 sound inventory on the perception and production of L2 sounds. Although, traditionally, these influences have been assessed as being manifestations of some sort of positive or 
negative transfer, it is important to bear in mind that, in actual fact, the notion of "phonetic transfer" itself is rather illusionary.

In spite of the extensive documentation of a cross-language similarity in the use of certain consonants and vowels in sound symbolism (Ohala 1984: 9), these similarities are, nevertheless, mere approximations at best, never phonological identicalness. While near approximations of consonants and vowels exist in different languages, even "similar consonants and vowels across languages are articulated in an entirely different fashion" (Erazmus 1980: 141). Furthermore, although phonological items which occur frequently across languages are expected to be easily perceived and produced and, conversely, phonological entities that are rarely found should be difficult to perceive and produce (Best and McRoberts 1995: 348), acquiring the sound system of a non-native language involves a complex of factors that sometimes manifest in unexpected ways.

\section{References}

Abrahamsson, Niclas. 2012. Age of onset and nativelike L2 ultimate attainment of morphosyntactic and phonetic intuition. Studies in Second Language Acquisition 34: 187-214.

Abrahamsson, Niclas-Kenneth Hyltenstam. 2009. Age of onset and nativelikeness in a second language: listener perception versus linguistic scrutiny. Language Learning 59(2): 249-306.

Alonso Alonso, M. Rosa. 2002. The Role of Transfer in Second Language Acquisition. Vigo: Universidade de Vigo, Servicio de Publicacións.

Best, Catherine T. 1995. A direct realist view of cross-language speech perception. In Strange, Winifred (ed.), Speech Perception and Linguistic Experience: Issues in Cross-Language Research, 171-204. Timonium, MD: York Press.

Best, Catherine T.-Gerald W. McRoberts. 2003. Infant perception of non-native consonant contrasts that adults assimilate in different ways. Language and Speech 46(2-3): 183-216.

Best, Catherine T.-Gerald W. McRoberts-Elizabeth Goodell. 2001. Discrimination of non-native consonant contrasts varying in perceptual assimilation to the listener's native phonological system. Journal of Experimental Psychology: Human Perception and Performance 109(2): 775-794.

Best, Catherine T.-Gerald W. McRoberts-Nomathemba M. Sithole. 1988. Examination of perceptual reorganization for non-native speech contrasts: Zulu click discrimination by English-speaking adults and infants. Journal of Experimental Psychology: Human Perception and Performance 14(3): 345-360.

Best, Catherine T.-Gerald W. McRoberts-Rosemarie LaFleur-Jean SilverIsenstadt. 1995. Divergent developmental patterns for infants' perception of 
two non-native consonant contrasts. Infant Behaviour and Development 18: 339-350.

Best, Catherine T.-Winifred Strange. 1992. Effects of phonological and phonetic factors on cross-language perception of approximants. Journal of Phonetics 20: 305-330.

Bley-Vroman. Robert. 1990. The logical problem of foreign language learning. Linguistic Analysis 20(1-2): 3-49.

Coetsem, Frans van. 2000. A General and Unified Theory of the Transmission Process in Language Contact. Heidelberg: Winter.

Corder, S. P. 1967. The significance of learner's errors. International Review of Applied Linguistics in Language Teaching 5(4): 161-170.

Cutler, Anne-Jacques Mehler-Dennis Norris-Juan Segui. 1992. The monolingual nature of speech segmentation by bilinguals. Cognitive Psychology 24: 381410.

Eimas, Peter D. 1974. Auditory and linguistic processing of cues for place of articulation by infants. Perception and Psychophysics 16(3): 513-521.

Epstein, Samuel David-Suzanne Flynn-Gita Martohardjono. 1996. Second language acquisition: Theoretical and experimental issues in contemporary research. Behavioral and Brain Sciences 19(4): 677-758.

Erazmus, Edward T. 1980. Articulatory setting and language teaching. In MidAmerica Linguistics Conference, 137-144.

https://kuscholarworks.ku.edu/bitstream/handle/1808/22845/malc_1980_ 137-144_Erazmus.pdf?sequence $=1$ \&isAllowed=y. (Last accessed: 10 April 2018).

Evans, Nicholas-Stephen C. Levinson. 2009. The myth of language universals: Language diversity and its importance for cognitive science. Behavioral and Brain Sciences 32(5): 429-492.

Flege, James Emil-Grace H. Yeni-Komshian-Serena Liu. 1999. Age constraints on second-language acquisition. Journal of Memory and Language 41: 78-104. Heller, Monica. 2006. Bilingualism. In Christine Jourdan-Kevin Tuite (eds), Language, Culture, and Society. Key Topics in Linguistic Anthropology, 156168. New York: Cambridge University Press.

Kedrova, G. E.-Borissoff, C. L. 2013. The concept of 'basis of articulation' in Russia in the first half of the $20^{\text {th }}$ century. Historiographia Linguistica $40(1)$ : 151-197. http://www.jbe-platform.com/content/journals/10.1075/hl.40.12.06ked. (Last accessed: 10 April 2018).

Kormos, Judit. 2006. Speech Production and Second Language Acquisition. Mahwah, New Jersey, London: Lawrence Erlbaum Associates.

Kuhl, Patricia K. 1994. Learning and representation in speech and language. Current Opinion in Neurobiology 4(6): 812-822. 
2010. Brain mechanisms in early language acquisition. Neuron 67(5): 713727.

Kuhl, Patricia K.-Barbara T. Conboy-Sharon Coffey-Corina-Denise PaddenMaritza Rivera-Gaxiola-Tobey Nelson. 2007. Phonetic learning as a pathway to language: New data and native language magnet theory expanded (NLM-e). Philosophical Transactions of the Royal Society B: Biological Sciences 363: 979-1000.

Kuhl, Patricia K.-Meltzoff, Andrew N. 1997. Evolution, nativism and learning in the development of language and speech. In Myrna Gopnik (ed.), The Inheritance and Innateness of Grammars, 7-44. New York: Oxford University Press.

Leavitt, John. 2006. Linguistic relativities. In Christine Jourdan-Kevin Tuite (eds), Language, Culture, and Society. Key Topics in Linguistic Anthropology, 47-81. New York: Cambridge University Press.

Lenneberg, Eric H. 1967. Biological Foundations of Language. New York: Wiley.

Liberman, Alvin M.-Ignatius G. Mattingly. 1985. The motor theory of speech perception revised. Cognition 21: 1-36.

Lively, S. E.-Pisoni, D. B. 1997. On prototypes and phonetic categories: A critical assessment of the perceptual magnet effect in speech perception. Journal of Experimental Psychology: Human Perception and Performance 23(6): 16651679.

Lowie, W. M.-Bultena, S. 2007. Articulatory settings and the dynamics of second language speech production. In J. Maidman (ed.), Proceedings of the PTLC 2007 Phonetics Teaching and Learning Conference, 24-26. http://www.phon. ucl.ac.uk/ptlc/. (Last accessed: 10 April 2018).

Lucas, Christopher. 2015. Contact-induced language change. In Claire BowernBethwyn Evans (eds), The Routledge Handbook of Historical Linguistics, 519536. London: Routledge.

Mattingly, Ignatius G. 1972. Speech cues and sign stimuli. American Scientist 60: 327-337.

Maye, Jessica-Janet F. Werker-LouAnn Gerken. 2002. Infant sensitivity to distributional information can affect phonetic discrimination. Cognition 82: B101-B111.

Mennen, Ineke-James M. Scobbie-Esther de Leeuw-Sonja Schaeffler-Felix Schaeffler. 2010. Measuring language-specific phonetic settings. Second Language Research 26(1): 13-41.

Miyawaki, Kuniko-Winifred Strange-Robert Verbrugge-Alvin M. LibermanJames J. Jenkins-Osamu Fujimura. 1975. An effect of linguistic experience: The discrimination of [r] and [l] by native speakers of Japanese and English. Perception and Psychophysics 18(5): 331-340. 
Ohala, John J. 1984. An ethological perspective on common cross-language utilization of $\mathrm{F}_{0}$ of voice. Phonetica 41: 1-16.

Ohala, Diane K. 2008. Phonological acquisition in a first language. In Jette G. Hansen Edwards-Mary L. Zampini (eds), Phonology and Second Language Acquisition, 19-41. Amsterdam/Philadelphia: John Benjamins.

Pisoni, David B. 1979. On the perception of speech sounds as biologically significant signals. Brain, Behavior and Evolution 16(5-6): 330-350.

Schaeffler, Sonja-James M.-Scobbie-Ineke Mennen. 2008. An evaluation of inter-speech postures for the study of language-specific articulatory settings. In Proceedings of the $8^{\text {th }}$ International Seminar on Speech Production. Strasbourg, 121-124. http://citeseerx.ist.psu.edu/viewdoc/summary?doi=10.1.1.515.1280. (Last accessed: 10 April 2018).

Selinker, Larry. 1972. Interlanguage. International Review of Applied Linguistics in Language Teaching 10: 209-231.

Snow, Catherine E.-Marian Hoefnagel-Höhle. 1978. The critical period for language acquisition: Evidence from second language learning. Child Development 49(4): 1114-1128.

Tarone, Elaine. 1983. On the variability of interlanguage systems. Applied Linguistics 4(2): 142-163.

Thomason, Sarah G.-Terrence Kaufman. 1988. Language Contact, Creolization and Genetic Linguistics. Berkeley, CA: University of California Press.

Wilson, Ian-Bryan Gick. 2006. Articulatory settings of French and English monolinguals and bilinguals. In $4^{\text {th }}$ Joint Meeting of the Acoustical Society of America and the Acoustical Society of Japan. http://web-ext.u-aizu.ac.jp/ $\sim$ wilson/publications/Wilson\&Gick2006ASA.pdf (Last accessed: 10 April 2018).

2014. Bilinguals use language-specific articulatory settings. Journal of Speech, Language, and Hearing Research 57: 361-373.

Wilson, Ian-Sunao Kanada. 2014. Pre-speech postures of second-language versus first-language speakers. Journal of the Phonetic Society of Japan 18(2): 106109. 